\title{
Hiperemezis Gravidarumun Gestasyonel Diyabet ve Gebelik Sonuçları Üzerine Etkisi
}

\author{
The Effect of Hyperemesis Gravidarum on Gestational Diabetes and Pregnancy Outcomes
}

$$
\text { Ali Cenk ÖZAY }{ }^{1} \text {, Özlen Emekçi ÖZAY }{ }^{1}
$$

1. Yakın Doğu Üniversitesi, Tip Fakültesi, KKTC

\section{$\ddot{O Z Z E T}$}

Amaç: Bulantı ve kusma, gebe kadınları\%\% 50-80'inde görülen en yaygin komplikasyondur. Gebe kadınların yaklassı $\%$ 1'i ilk trimesterde şiddetli bulantı ve kusma yaşarlar ve hiperemezis gravidarum (HG) tanisı alırlar. $H G$ 20. gebelik haftasindan önce hastaneye yatışın ana nedenidir. Önceki çalışmalarda, insülin duyarlilığl, $H G$ ve gestasyonel diabetes mellitus (GDM) arasında bir iliski kurulmuștur. Bu çalıșmada, HG'nin, GDM ve gebelik sonuçları üzerindeki etkisini değerlendirmek amaçlanmuştır.

Gerecler ve Yöntem: Bu retrospektif çalıșma 1 Mart 2015-30 Eylül 2017 tarihleri arasinda Konya Akşehir Devlet Hastanesi'nde yapıldl. Calıșmaya toplam 100 hasta dahil edildi (n: 46 $H G, n: 54$ kontrol). GDM için tarama gebelik sirasında bir kez gerçekleştirildi. GDM tanısı, ikinci trimesterde, 24-28 gebelik haftasından 75 g OGTT ile konuldu. Başlıca değerlendirilen parametreler; gestasyonel diyabet, gebeliğe bağll hipertansiyon, fetal doğum ăgrrlı̆̆l, preterm doğum ve fetal cinsiyet idi. Istatistiksel analiz SPSS 15.0 kullanilarak yapıld $. p<0.05$ istatistiksel olarak anlamlı kabul edildi.

Bulgular: Illk muayenede, iki grup arasında maternal yaş ve VKI açısından anlamlı bir farklılık gözlenmedi. GDM prevalansl, gebeliğe bağlı hipertansiyon, fetal doğum ağırliğl, preterm doğum ve fetal cinsiyet açısından gruplar arasinda istatistiksel olarak anlamlı fark bulunmadr.

Sonuç: Literatürde hiperemezis gravidarumun maternal ve fetal sonuçlar üzerine olumsuz etkilerini gösteren birçok çalışma vardır. Çalışmamızda hiperemezis gravidarumun olumsuz gebelik sonuçları ile ilişsili olmadiğ bulunmuştur. Bu çalışmanın kısitlılığ hasta sayısinin az olmasıdır. Hiperemezis gravidarumun uzun dönem etkilerini tanımlamak için daha kapsamlı çalışmalara ihtiyaç vardır.

Anahtar Kelimeler: hiperemezis gravidarum, gestasyonel diyabet, gebelik sonuçları

\section{ABSTRACT}

Objective: Nausea and vomiting in pregnancy is the most common complication that observed in \%50-80 of pregnant women. Approximately \%1 of pregnant women experience severe nausea and vomiting during the first trimester and are diagnosed with hyperemesis gravidarum $(H G)$. $H G$ is the major reason for hospitalization before 20 gestational weeks. A relationship between insulin sensitivity, $H G$, and gestational diabetes mellitus (GDM) has been established. In this study, we aimed to assess the impact of HG on GDM and pregnancy outcomes.

Material and Methods: This retrospective study was conducted at Konya Akşehir State Hospital between 1st March 2015 and 30th September 2017.

İetişim:

Sorumlu Yazar: Ali Cenk ÖZAY

Adres: Yakın Doğu Üniversitesi, Tip Fakültesi Hastanesi, Yakın

Doğu Bulvarı, PK: 99138 Lefkoşa, Kıbrıs, KKTC

Tel: +90 (392) 2236464 / +90 (392) 6802000

E-Posta: dr.alicenk@hotmail.com

Makale Geliş: 29.06.2018

Makale Kabul: 09.02.2019

DOI: http://dx.doi.org/10.16948/zktipb.439085
A total of 100 women included in this study (n:46 hyperemesis, $n: 54$ control). Screening for GDM was performed once during pregnancy. GDM diagnosis was obtained with a 75-g OGTT, during the second trimester, from 24-28 weeks of gestation. Main outcomes were gestational diabetes, pregnancy-induced hypertension, fetal birth weight, preterm birth and fetal sex. Statistical analysis was performed using SPSS 15.0. $p<0.05$ was considered as statistically significant.

Results: At initial examination, no significant differences in maternal age and BMI were observed between the two groups. We found no statistical difference between the groups in the prevalence of GDM, pregnancy-induced hypertension, fetal birth weight, preterm birth and fetal sex.

Conclusion: In the literature, there are many studies that shows negative effects of $H G$ on maternal and fetal outcomes. In our study, it was found that HG is not associated with adverse pregnancy outcomes. The lack of this study is the small number of patients. More extensive studies are needed to define long term effects of $H G$.

Keywords: hyperemesis gravidarum, gestational diabetes, pregnancy outcomes

\section{GİRIS}

Bulantı ve kusma, gebeliklerin yaklaşık \%5080 'ini etkilemektedir (1). İlk trimesterde ciddi bulant1 ve kusma nedeniyle hiperemezis gravidarum (HG) tanısı konulan hasta ise yaklaşı $\% 1$ oranındadır (2). HG oluşma mekanizması tam olarak bilinmemekle birlikte risk faktörleri arasında düșük vücut kitle indeksi $(3,4)$, yüksek Bhcg düzeyleri (5), yüksek östrojen seviyeleri (6), dişi fetus (7) veya aile öyküsü (8) gibi birçok neden sayılmaktadır.

Ciddi HG durumlarında inatçı kusmalara bağlı olarak ketonüri, artmış kan üre seviyesi, artmış hematokrit, dehidratasyon, elektrolit imbalansı, kilo kaybı ve metabolik bozukluklardan biri veya birkaçı birlikte görülebilmektedir (9). HG, gebeliğin ilk yarısında hospitalizasyon endikasyonlarının en s1k nedenlerinden biridir ve \%19-30 oranında hastada tekrarlayan hospitalizasyon söz konusudur $(2,10)$. Literatürde, hiperemezis gravidarumun gebelik sonuçları ve GDM üzerine etkisini araştıran çalışmalarda çelişen sonuçlar izlenmektedir. Önceki çalışmalarda insülin duyarlılığ 1 , HG ve GDM arasında ilişki olduğu öne sürülmüş̧ $(11,12)$, açlık durumunun ve düşük kalorili diyetin insülin rezistansını

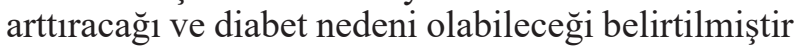
(13). Gebelik kusmalarının, düşük doğum ağırlığı $(14,15)$, gestasyonel diyabet taramasında yüksek pozitiflik oranları (11), gebelikte düşük kilo alımı (16) ile ilişkili olduğunu öne süren çalışmalar mevcuttur. Bunun yanında HG ile gestasyonel diyabetin ilişkili olmadığını tespit eden çalışmalar da bulunmaktadır $(16,17)$. 
Bu çalışmada, literatürde yer alan çelişkili sonuçlardan yola çıkarak, HG tanısıyla hospitalize edilmiş hastalarda, ilerleyen gebelik haftalarında GDM riskinin, ikinci olarak ise gebelik sonuçlarına etkisinin araştırılması amaçlanmıştır.

\section{GEREÇ ve YÖNTEM}

Bu çalışma, retrospektif olarak yapılmıştır. Çalışma grubuna 1 Mart 2015 ile 30 Eylül 2017 tarihleri arasında Konya Akşehir Devlet Hastanesi'nde doğum yapmış ve önceki takiplerinde en az bir kere HG tanısı nedeniyle yatışı yapılmış olan hastalar dahil edilmiştir. Kontrol grubuna ise aynı dönemlerde doğum yapmış, ek hastalığı olmayan, sağl1klı, takipli gebelikler alınmıştır. Çalışmada tüm veriler Konya Akşehir Devlet Hastanesi veri tabanı ve hasta kayıt defterleri ile dosyalarından elde edilmiştir. Çalışmaya 46 HG tanısı olan hasta ile 54 kontrol hastası alınmıştır. Çalışmaya katılan tüm hastalardan onam alınmıştır.

Hiperemezis gravidarum tanısı; gebeliğin birinci üç ayında, dirençli kusması ve yeme-içme açısından ciddi intolerans olması, dehidratasyon gelişmesi, elektrolit imbalansı veya metabolik bozukluk saptanmas1 veya en az $\% 5$ ve üzeri kilo kaybı olmas1 ile konulmuştur.

Dışlanma kriterleri; 18 yaş altı ve 35 yaş üstü gebelikler, OGTT testini yaptırmak istemeyen hastalar, hastanemiz dışında doğum yapan hastalar, gestasyonel diyabet açısından risk faktörü olan hastalar, herhangi bir sistemik enfeksiyon varlığı, üriner sistem enfeksiyonları, gastrointestinal sistem enfeksiyonları, gastroenterit, akut batın oluşturabilecek jinekolojik ve jinekoloji dışı durumlar, hipertiroidi, diyabetes mellitus gibi endokrin hastalıklar, gebeliğin indüklediği hipertansiyon dişındaki hipertansiyon nedenleri, 24 haftadan önce doğum veya abortus ile sonuçlanmış gebelikler olarak belirlenmisstir. Hastane kayıtlarında ve hasta dosyalarında eksik bilgi olan hastalar ile çalışmaya katılmayı istemeyen hastalar çalışmaya dahil edilmemiştir. Önceki gebeliğinde GDM öyküsü, ileri maternal yaş, makrozomik doğum öyküsü ( $>4000$ gram), obezite (VKI $>30 \mathrm{~kg} / \mathrm{m} 2$ ), birinci derece akrabada diyabet öyküsü, önceki gebelikte fetüste malformasyon öyküsü, bozulmuş glukoz toleransı, glikozüri ve diyabete yatkınlık yaratabilecek diğer endokrin hastalık durumları, GDM açısından risk faktörleri olarak belirlenmiştir.

Tüm hastalara tek sefer 24-28. gestasyonel haftalar arasında 75 gram oral glukoz tolerans testi (OGTT) yapılmıştır.75 gram OGTT sonuçlarında GDM tanıs1; açlık, 1. saat ve 2. saat serum glikoz seviyelerinden en az birinin yüksek olması ile konulmuştur. Cut off değerleri; açlık serum glikozu $\geq 92 \mathrm{mg} / \mathrm{dL}$, 1. saat $180 \mathrm{mg} / \mathrm{dL}, 2$. saat $153 \mathrm{mg} / \mathrm{dL}$ olarak alınmıştır (18). Gebeliğin indüklediği hipertansiyon her muayenede tansiyon ölçülerek taranmıştır. 20. gebelik haftasından sonra, en az 4 saat ara ile ölçülen iki ölçümde tansiyon değerleri $\geq 140 / 90 \mathrm{mmHg}$ olan hastalara gebeliğin indüklediği hipertansiyon tanısı konulmuştur.
Hastaların ek olarak yaş, parite, vücut kitle indeksi (ilk poliklinik muayenesinde, OGTT sırasında ve doğumda), gebeliğin indüklediği hipertansiyon varlığı, fetal doğum ağırlığ 1 , düşük doğum ağırl1$\breve{g}_{1}(<2500 \mathrm{~g})$, doğum şekli, doğumdaki gestasyonel hafta verileri, preterm doğum ( $<37$ hafta) ve fetal cinsiyet kayıt edilmiştir.

İstatistiksel analizler için SPSS 15 programı kullanılmıştır. P değeri $<0.05$ istatistiksel olarak anlamlı kabul edilmiştir.

\section{BULGULAR}

Çalışmanın sonuçlarında, hastaların yaşları, başvuru sırasındaki ve OGTT sırasındaki vücut kitle indeksleri, pariteleri, gruplar arasında benzerlik göstermiştir. Doğum için başvuruda yapılan değerlendirmede, vücut kitle indeksleri HG grubunda anlamlı olarak düşük izlendi (Tablo 1).

Tablo 1: Hastaların demografik özellikleri.

\begin{tabular}{|l|l|l|l|}
\hline & HG (n:46, \%) & Kontrol (n:54, \%) & $\mathrm{p}$ \\
\hline Yaş & $25.84 \pm 6.21$ & $26.43 \pm 6.07$ & 0.08 \\
\hline Parite & & & \\
\hline Primipar & $26(56.5)$ & $24(44.4)$ & 0.33 \\
\hline Multipar & $20(43.5)$ & $30(55.6)$ & 0.56 \\
\hline İlk başvuru VKİ & $26.54 \pm 4.7$ & $26.97 \pm 4.2$ & 0.10 \\
\hline OGTT sırasında VKİ & $27.18 \pm 3.41$ & $28.97 \pm 4.12$ & 0.06 \\
\hline Doğumda VKİ & $27.42 \pm 2.97$ & $29.81 \pm 3.22$ & 0.02 \\
\hline
\end{tabular}

HG: Hiperemezis gravidarum, VKI: vücut kitle indeksi, OGTT: oral glikoz tolerans testi. $\boldsymbol{P}<0.05$ istatistiksel olarak anlamlı kabul edilmiştir. Bağımsız gruplar t testi yapılmıştır

Gestasyonel diyabet, gebeliğin indüklediği hipertansiyon, doğum şekli, doğumdaki gebelik haftalar1, preterm doğum, fetal cinsiyet açısından gruplar arasi anlamlı farklilık saptanmadi (Tablo 2).

Tablo 2: Gebelik ve doğum sonuçları.

\begin{tabular}{|c|c|c|c|}
\hline & $\begin{array}{l}\text { Hiperemezis } \\
\text { gravidarum } \\
(\mathrm{n}: 46, \%)\end{array}$ & $\begin{array}{l}\text { Kontrol } \\
(\mathrm{n}: 54, \%)\end{array}$ & $\mathrm{p}$ \\
\hline Gestasyonel diyabet & $4(8.7)$ & $4(7.4)$ & 0.24 \\
\hline $\begin{array}{l}\text { Gebeliğin indüklediği } \\
\text { hipertansiyon }\end{array}$ & $3(6.5)$ & $3(5.6)$ & 0.48 \\
\hline Doğum haftası & $39,1 \pm 2.2$ & $38.9 \pm 2.4$ & 0.79 \\
\hline \multicolumn{4}{|l|}{ Doğum şekli } \\
\hline Normal doğum & $33(71.7)$ & $38(70.4)$ & 0.29 \\
\hline Sezaryen & $13(28.3)$ & $16(29.6)$ & \\
\hline \multicolumn{4}{|l|}{ Fetal cinsiyet } \\
\hline $\mathrm{K}_{1 \mathrm{Z}}$ & $24(52.2)$ & $28(51.9)$ & 0.18 \\
\hline Erkek & $22(47.8)$ & $26(48.1)$ & 0.55 \\
\hline Ortalama fetal ağırlık (kg) & $2.85 \pm 0.98$ & $2.90 \pm 0.87$ & 0.32 \\
\hline Düşük doğum ağırlığg1 & $5(10.9)$ & $6(11.1)$ & 0.40 \\
\hline Preterm doğum & $2(4.3)$ & $3(5.6)$ & 0.33 \\
\hline
\end{tabular}

$\boldsymbol{P}<0.05$ istatistiksel olarak anlamlı kabul edilmiştir. Bă̆ımsız gruplar t testi yapılmıștır 


\section{TARTIŞMA}

Hiperemezis gravidarumun neden olduğu metabolik problemlerin bazen çok ciddi dehidratasyona, elektrolit bozukluklarına yol açabileceği bilinmektedir. Hiperemezis gravidarumun da neden olabileceği açlık durumlarında selüler metabolik yolak glikolizis yönünden glikogenezise dönüşmektedir.

$\mathrm{Bu}$ süreçte yağ dokusundan elde edilen yağ asitleri glikoz üretiminde kullanılmaktadır. Bu yolakta eş zamanlı olarak üretilen ketona ve yağ asitlerine uzun süreli maruziyetin pankreasta bulunan $\beta$ hücrelerine inhibe edici etki oluşturduğu ve bunun sonucunda glikoz intoleransı gelişebileceği öne sürülmüştür $(19,20)$. Bundan yola çıkarak hiperemezis gravidarumun gestasyonel diyabete yatkınlık oluşturabileceği düşünülebilir.

$\mathrm{Bu}$ çalışmada her iki grup arasında GDM tanısı açısından anlamlı fark izlenmemiştir. Ohara ve ark. (11) yapmış oldukları çalışmalarında, birinci trimesterde GDM taramasında hiperemezis grubunda pozitiflik oranları anlamlı olarak yüksek iken, 2428. gestasyonel haftalar aras1 yaptıklar1 $75 \mathrm{~g}$ OGTT testinde bizimle benzer olarak gruplar aras1 GDM açısından fark bulmamışlardır. Bizim çalışmamızda birinci trimesterde GDM tarama testi yapilmamıștır. Hastaların hepsine hiperemezis tedavisi verilmesi nedeniyle, $75 \mathrm{~g}$ OGTT test sonuçlarında gruplar arası farklılık saptanmamış olabilir. Ayr1ca HG semptomlarının birinci trimesterden sonra azalmaya başlaması ve birçok hastada tamamıyla geçmesi nedeniyle açlığın neden olduğu metabolik yolak değişiklikleri normale dönmesi, bu sonucun elde edilmesinde etkili olabilir.

Madendağ ve ark. çalışmalarında (21) hiperemezis grubunda bizim çalışmamızla benzer şekilde GDM açısından risk artışı saptamamışlardır. Hatta bu çalışmada hiperemezis grubunda 1 . ve 2 . saat kan şekeri değerlerinin kontrol grubuna göre anlamlı olarak daha düşük olduğunu gözlemlemişlerdir. Kilo vermenin GDM ve tip 2 diyabet açısından koruyucu etkisinin olduğu düşünüldüğünde, bu sonucun HG sırasında hastaların kilo kaybetmesine bağlı olabileceği öne sürülebilir $(22,23)$. Bizim çalışmamıda da HG grubunda, ilerleyen gebelik haftasiyla birlikte, kontrol grubuna kıyasla VKİ değerlerinin daha düşük olduğu ve doğumda bu farkın istatistiksel olarak anlamlı olduğu görülmüştür. Doods ve ark.' da çalışmalarında hipermezis tanısı olan hastalarda gebelik boyunca alınan kilonun daha az olduğunu saptamışlardır (16). HG hastalarında daha az kilo alımı olması, açlığın yarattı̆̆ insülin dirençli durumu nötralize ediyor olabilir. Bu konudaki belirsizlik ve çelişkilerin netleştirilebilmesi için geniş katılımlı prospektif çalışmaların yapılması gerektiğini düşünüyoruz.

Çalışmamızda hiperemezis gravidarumun, gebeliğin indüklediği hipertansiyon üzerine etkisinin olmadığını saptadık. Bu bulgu literatür ile uyumlu görünmektedir (14, 17). Literatürde hiperemezis gravidarumun gebelik sonuçları üzerine etkisini araştıran yayınlarda birbiriyle çelişen, farklı sonuçlar elde edildiği izlenmiştir. Kuru ve ark. hiperemezis gravidarumun gebelik sonuçları üzerine etkisinin olmadığını göstermiştir (17). Doods ve ark. , özellikle gebeliği boyunca 7 kg'dan az kilo artış1 olan HG hastalarında, sezaryen oranlarının bir miktar daha yüksek, 5. dakika APGAR skorunun 7'den az, preterm doğum ve düşük doğum ağırlığının daha sık olduğunu belirtmişlerdir (16). Biz çalışmamızda APGAR skorunu incelemedik. Ancak doğum şekli, preterm doğum, fetal doğum ağırlığ ve doğum haftası açısından bizim çalışmamızda herhangi bir anlamlı değişiklik görülmemiştir.

Kuru ve ark.'nın (17) çalışmalarında tespit ettiği gibi, bizim çalışmada da, HG ile fetal cinsiyet ilişkisinde anlamlı farklılık izlenmemiştir. Ancak, literatürde bunun tersini iddia eden çalışmalar mevcuttur $(14,24,25)$. Bu durum, hasta sayısının göreceli olarak az olmasindan kaynaklanabilir.

Bu çalışmanın kısıtlılıkları; retrospektif oluşu, hasta sayısının göreceli olarak az olması, hastaların uzun dönem sonuçlarının incelenmemesi, hastaların aldıkları tedavilerin süresinin ve çeşitlerinin bilinmemesidir.

\section{SONUÇ}

Hiperemezis gravidarum, gebeliğin ilk trimesterinde en sık görülen hastaneye yatış endikasyonlarından biridir. $\mathrm{Bu}$ durumun gebelik ve fetus üzerine olası etkilerini araştıran çok sayıda çalışma bulunmaktadır. Bulgularımız, hiperemezis gravidarumun, gestasyonel diyabet ve diğer gebelik sonuçları üzerine olumsuz etkisinin olmadığını göstermiştir. Ancak literatürde birçok farklı sonuç olması ve bizim çalışmamızın kısıtlılıkları nedeniyle prospektif, geniş tabanlı ve uzun dönem sonuçların da incelendiği çalışmalara ihtiyaç olduğu düşünülmektedir.

\section{KAYNAKLAR}

1. Jarvis S, Nelson-Piercy C. Management of nausea and vomiting in pregnancy. BMJ 2011;342:d3606.

2. Bailit JL. Hyperemesis gravidarium: Epidemiologic findings from a large cohort.Am J Obstet Gynecol. 2005 Sep;193(3 Pt 1):811-4.

3. Helseth R, Ravlo M, Carlsen SM, Vanky EE. Androgens and hyperemesis gravidarum: a case-control study. Eur J Obstet Gynecol Reprod Biol. 2014;175:167-71.

4. Fell DB, Dodds L, Joseph KS, Allen VM, Butler B. Riskfactors for hyperemesis gravidarum requiring hospital admission during pregnancy. Obstet Gynecol. 2006; 107(2 Pt 1):277-84.

5. Goodwin TM, Hershman JM, Cole L. Increased concentration of the free beta-subunit of human chorionic gonadotropin in hyperemesis gravidarum. Acta Obstet Gynecol Scand. 1994;73:770-772.

6. Depue RH, Bernstein L, Ross RK, Judd HL, HendersonBE. Hyperemesis gravidarum in relation to estradiol levels, pregnancy outcome, and other maternal factors: a seroepidemiologic study. Am J Obstet Gynecol. 1987;156:1137-1141.

7. Tan PC, Jacob R, Quek KF, Omar SZ. The fetal sex ratio and metabolic, biochemical, haematological and clinical indicators of severity of hyperemesis gravidarum. BJOG 2006; 113:733737. 
8. Vikanes A, Skjaerven R, Grjibovski AM, Gunnes N, Vangen S, Magnus $P$. Recurrence of hyperemesis gravidarum a cross generations: population based cohort study. BMJ. 2010;340:c2050.

9. Ismail S.K.,Kenny L. Review on hyperemesis gravidarum. Best Pract Res Clin Gastroenterol. 2007;21:755-69.

10.Fejzo MS, MacGibbon KW, Romero R, Goodwin TM, Mullin $P M$. Recurrence risk of hyperemesis gravidarum. J Midwifery Women Health. 2011;56:132-6.

11. Ohara R, Obata-Yasuoka M, Abe K, et al. Effect of hyperemesis gravidarum on gestational diabetes mellitus screening. Int $J$ Gynaecol Obstet. 2016;132:156-158.

12. Ayyavoo A, Derraik JG, Hofman PL, et al. Severe hyperemesis gravidarum is associated with reduced insulin sensitivity in the off spring in childhood. J Clin Endocrinol Metab. 2013;98:3263-3268

13. Koffler M, Kisch ES. Starvation diet and very-low-calorie diets may induce insulin resistance and overt diabetes mellitus. $J$ Diabet Complicat. 1996;10(2):109-12.

14. Petry CJ, Ong KK, Beardsall K, Hughes IA, Acerini CL, Dunger DB. Vomiting in pregnancy is associated with a higher risk of low birth weight: a cohort study. BMC Pregnancy Childbirth. 2018 May 4;18(1):133. doi: 10.1186/s 12884-018-1786-1.

15. Hastoy A, LienTran P, Lakestani $O$, Barau G, Gérardin P, Boukerrou M.Hyperemesis gravidarum and pregnancy outcomes. J Gynecol Obstet Biol Reprod. 2015;44:154-63.

16. Dodds L, Fell DB, Joseph KS, Allen VM, Butler B. Outcomes of pregnancies complicated by hyperemesis gravidarum. Obstet Gynecol. 2006 Feb;107(2 Pt 1):285-92.

17. Kuru O, Sen S, Akbayır O, Goksedef BP, Ozsürmeli M, Attar E, Saygll H. Outcomes of pregnancies complicated by hyperemesis gravidarum. Arch Gynecol Obstet. 2012 Jun;285(6):151721.
18. Metzger BE, Gabbe SG, Persson B, Buchanan TA, Catalano PA, Damm P, Dyer AR, Leiva Ad, Hod M, Kitzmiler JL, Lowe LP, McIntyre HD, Oats JJ, Omori Y, Schmidt MI. International association of diabetes and pregnancy study groups recommendations on the diagnosis and classification of hyperglycemia in pregnancy. Diabetes Care. 2010 Mar; 33 (3): 676-82. doi: $10.2337 / d c 09-1848$

19. Zhou YP, Grill V. Long term exposure to fatty acids and ketones inhibits B-cell functions in human pancreatic islets of Langerhans. J Clin Endocrinol Metab 1995;80(5): 1584-90.

20. Duska F, Andel M, Kubena A, Macdonald IA. Effects of acute starvation on insulin resistance in obese patients with and without type 2 diabetes mellitus. Clin Nutr 2005; 24(6):1056-64.

21. Madendag Y, Sahin E, Madendag Col I, Eraslan SM, Tayyar AT, Ozdemir F, Acmaz $G$, Senol $V$. The effect of hyperemesis gravidarum on the $75 \mathrm{~g}$ oral glucose tolerance test screening and gestational diabetes mellitus. J Matern Fetal Neonatal Med. 2018 Aug;31(15):1989-1992.

22. Bennett CJ, Walker RE, Blumfield ML, Gwini SM, Ma J, Wang F, Wan Y, Dickinson H, Truby H. Interventions designed to reduce excessive gestational weight gain can reduce the incidence of gestational diabetes mellitus: A systematic review and meta-analysis of randomised controlled trials. Diabetes Res Clin Pract. 2018 Jul;141:69-79.

23. Tuomilehto J, Lindström J, Eriksson JG, et al. Prevention of type 2 diabetes mellitus by changes in lifestyle among subjects with impaired glucose tolerance. $N$ Engl J Med. 2001; 344: 1343-1350.

24. Sørensen HT, Thulstrup AM, Mortensen JT, Larsen H, Pedersen L. Hyperemesis gravidarum and sex of child. Lancet. 2000 Jan 29;355(9201):407.

25. Basso O, Olsen J. Sex ratio and twinning in women with hyperemesis or pre-eclampsia. Epidemiology. 2001 Nov;12(6):7479. 